\title{
Genetic population of Plasmodium knowlesi during pre-malaria elimination in Thailand
}

\author{
Rungniran Sugaram ${ }^{1}$, Patcharida Boondej ${ }^{1}$, Suttipat Srisutham² ${ }^{2}$ Chanon Kunasol ${ }^{3}$, Watcharee Pagornrat ${ }^{3}$, \\ Usa Boonyuen ${ }^{4}$, Arjen M Dondorp ${ }^{3,5}$, Aungkana Saejeng ${ }^{1}$, Prayuth Sudathip ${ }^{1}$ and Mallika Imwong ${ }^{4^{*}}$ (D)
}

\begin{abstract}
Background: Thailand is committed to eliminating malaria by 2024. From 2013 to 2020, the total number of malaria cases have decreased, from 37,741 to 4474 (an 88.1\% reduction). However, infections with Plasmodium knowlesi, a monkey malarial pathogen that can also infect humans, have been increasingly observed. This study focused on the molecular analysis of $P$. knowlesi parasites causing malaria in Thailand.

Methods: Under Thailand's integrated Drug Efficacy Surveillance (iDES), which includes drug-resistance monitoring as part of routine case-based surveillance and responses, specimens were collected from malaria patients $(n=966)$ between 2018 and 2020. Thirty-one mono P. knowlesi infections (3.1\%), most of which were from eastern and southern Thailand, were observed and confirmed by nested PCR assay and DNA sequencing. To evaluate whether these pathogens were from different lineages, cluster analysis based on seven microsatellite genotyping markers and the merozoite surface protein 1 (pkmsp 1) gene was carried out. The $P$. knowlesi pyrimethamine resistance gene dihydrofolate reductase ( $p k d h f r)$ was sequenced and homology modelling was constructed.
\end{abstract}

Results: The results of analysing the seven microsatellite markers and $p k m s p 1$ sequence demonstrated that $P$. knowlesi parasites from eastern Thailand were of the same lineage as those isolated in Cambodia, while the parasites causing malaria in southern Thailand were the same lineage as those isolated from Malaysia. The sequencing results for the pkdhfr genes indicated the presence of two mutations, Arg34Leu and a deletion at position 105. On analysis with homology modelling, the two mutations were not associated with anti-malarial drug resistance.

Conclusions: This report compared the genetic populations of P. knowlesi parasites in Thailand from 2018 to 2020 and have shown similar lineages as those isolated in Cambodia and Malaysia of $P$. knowlesi infection in Thailand and demonstrated that the P. knowlesi parasites were of the same lineages as those isolated in Cambodia and Malaysia. The parasites were also shown to be sensitive to pyrimethamine.

Keywords: Plasmodium knowlesi, pkmsp1, pkdhfr

\section{Background}

Between 2010 and 2018, the incidence of malaria declined globally from 71 to 57 cases per 1000 head of at-risk populations. However, malaria still kills over 400,000 individuals every year [1]. In the Greater Mekong

\footnotetext{
*Correspondence: noi@tropmedres.ac; mallika.imw@mahidol.ac.th

${ }^{4}$ Department of Molecular Tropical Medicine and Genetics, Faculty of Tropical Medicine, Mahidol University, Bangkok, Thailand

Full list of author information is available at the end of the article
}

subregion (GMS), including Cambodia, China (Yunnan Province), Lao People's Democratic Republic, Myanmar, Thailand, and Vietnam, the reported number of malaria cases fell by $76 \%$ between 2010 and 2018, and malaria deaths fell by $95 \%$ over the same period [1]. Thailand is committed to eliminating malaria by 2024 . Between 2013 and 2020, the overall malaria incidence decreased from 37,741 to 4474 cases ( $88.1 \%$ reduction). The incidence of both Plasmodium falciparum and Plasmodium vivax malaria is declining, but the proportion of the

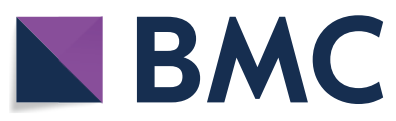

(c) The Author(s) 2021, corrected publication 2022. Open Access This article is licensed under a Creative Commons Attribution 4.0 International License, which permits use, sharing, adaptation, distribution and reproduction in any medium or format, as long as you give appropriate credit to the original author(s) and the source, provide a link to the Creative Commons licence, and indicate if changes were made. The images or other third party material in this article are included in the article's Creative Commons licence, unless indicated otherwise in a credit line to the material. If material is not included in the article's Creative Commons licence and your intended use is not permitted by statutory regulation or exceeds the permitted use, you will need to obtain permission directly from the copyright holder. To view a copy of this licence, visit http://creativecommons.org/licenses/by/4.0/. The Creative Commons Public Domain Dedication waiver (http://creativecommons.org/publicdomain/zero/1.0/) applies to the data made available in this article, unless otherwise stated in a credit line to the data. 
two species has changed, with $P$. falciparum accounting for $5.7 \%(257 / 4474)$ of cases and P. vivax for $91.6 \%$ (4099/4474) in 2020 [2].

One of the Plasmodium species that infects humans, Plasmodium knowlesi [3], is a natural parasite of the long-tailed macaque, Macaca fascicularis and the pigtailed macaque, Macaca nemestrina. Human malarial infection with this parasite was first reported in 1965 [4], and a second case presented in 1971 in Malaysia [5]. Plasmodium knowlesi infections have also shown distribution across the Greater Mekong Subregion (GMS), and previous $P$. knowlesi infections in the GMS have been recorded in Malaysia [6-9], Thailand [10-12], Myanmar [13, 14], Laos [15, 16], Vietnam [17, 18], and Cambodia [19]. The distribution of $P$. knowlesi may obstruct the malaria elimination agendas of countries of the GMS of Southeast Asia, especially due to asymptomatic cases, which have been previously reported [20].

In Thailand, the malaria information system set up by the National Malaria Control Programme (NMCP) of Thailand does not include information on P. knowlesi infections that occurred during the early stages of the system's development; this is because the programme used Giemsa staining of thick and thin blood films and the pfHRPII-pLDH antigen rapid diagnostic test (pf-pan RDT) for diagnosis [21], which do not clearly distinguish P. knowlesi from other Plasmodium species. The NMCP of Thailand began using molecular techniques for confirmation as the most effective tool for malaria verification in quality control and quality assurance. Plasmodium knowlesi cases were subsequently detected in malaria patients who had visited the forest habitats of $M$. fascicularis and $M$. nemestrina macaques.

The present study aimed to analyse the genetic population of $P$. knowlesi parasites in Thailand and compare them with previous published findings of parasites isolated from Thailand [22, 23], Cambodia [20] and Malaysia [24-26]. Network analyses based on microsatellite markers were performed and constructed a phylogenetic tree based on the nucleotide sequences of the P. knowlesi merozoite surface protein 1 gene ( $p k m s p 1)$. Furthermore, the $P$. knowlesi dihydrofolate reductase gene was isolated and analysed for mutations, and homology modelling of PkDHFR mutants was conducted.

\section{Methods}

\section{Study sites and sample collection}

Under the Thailand iDES, between 2018 and 2020, samples were collected from malaria patients $(\mathrm{n}=966)$ to confirm Plasmodium species infection. The DNA samples were extracted using QIAmp DNA Mini Kit (Qiagen, Hilden, Germany) following the manufacturer's instructions. Nested PCR based on the 18s rRNA gene was performed following published protocol [27]. The amplified PCR product was purified using FavorPrep (Favorgen, Taiwan) and sent to Macrogen (South Korea) for DNA sequencing. Nucleotide and amino acid sequences of $18 r R N A$ were searched against the NCBI database using blastn (https://blast.ncbi.nlm.nih.gov/Blast.cgi).

\section{Molecular markers analysis}

DNA samples were analysed for $P$. knowlesi microsatellite markers, NC03_2, CD05_06, NC09_1, NC10_1, CD11_157, NC12_2, and CD13_107, following a previous protocol [24]. Amplification of $p k m s p 1$ and full length $p k d h f r$ was performed by nested PCR following previously published protocols [24]. The amplified PCR products of pkmsp1 (covering nucleotides 4578 to 5376) and $p k d h f r$ (covering nucleotides 1 to 708) were purified using the FavorPrep PCR purification kit. The purified PCR products of $p k m s p 1$ and $p k d h f r$ were outsourced to Macrogen (South Korea) for sequencing. Nucleotide and amino acid sequences of these genes were aligned and compared with the reference sequences from $P$. knowlesi (accession no AM910987).

\section{Network analysis}

The results of the analysis of $P$. knowlesi microsatellite genotyping markers were used in the cluster analysis using Network 10 software (https://www.fluxus engineering.com/sharenet.htm), which is based on Median Joining algorithms. Previously published $P$. knowlesi microsatellite data from asymptomatic infections from Cambodia $(\mathrm{n}=8)$ [20], Peninsular Malaysia $(\mathrm{n}=16)$, Sarawak, and Sabah $(\mathrm{n}=22)$ and P. knowlesi infections from wild macaques (long-tailed and pig-tailed macaques) in Kapit $(n=18)$ [24] were combined for analysis to demonstrate the association between $P$. knowlesi parasites isolated from different parts of Thailand and those isolated from Cambodia and Malaysia.

\section{Phylogenetic tree analysis}

To demonstrate the relationship between P. knowlesi parasites isolated in Thailand, Malaysia, and Cambodia, the DNA sequencing data of $P$. knowlesi merozoite surface protein 1 ( $p k m s p 1)$ gene obtained in this study and previous data $[22,23,25,26]$ were used to construct a phylogenetic tree, using MEGA X (https://www.megasoftware. net/) based on neighbour-join (NJ) and BioNJ algorithms with branch lengths measured as the number of substitutions per site.

\section{Homology modelling of PkDHFR mutants}

Homology models of the wild type (WT) PkDHFR and two mutant (Arg34Leu and Thr105 deletions) proteins in complex with the inhibitor (pyrimethamine) were 
constructed, using SWISS-MODEL server (https://swiss model.expasy.org/interactive) based on the $\mathrm{x}$-ray structure of PvDHFR at a resolution of $1.90 \AA$ (PDB ID: 2BL9) [28]. The models were validated by PROCHECK [29].

\section{Results}

\section{Plasmodium knowlesi infection in Thailand}

Of the 966 malaria collected samples, 31 (3.2\%) monoinfections with $P$. knowlesi were confirmed by nested PCR assay and DNA sequencing. The samples collected from eastern Thailand included isolates from Surin $(\mathrm{n}=$ $1)$, Chanthaburi $(n=1)$, Trat $(n=10)$, and those from southern Thailand included isolates from Prachuap Khiri
Khan ( $\mathrm{n}=2)$, Chumphon ( $\mathrm{n}=13)$, Ranong $(\mathrm{n}=1)$, Surat Thani $(\mathrm{n}=1)$, and Phang-nga $(\mathrm{n}=2)$ in 2018 and 2019 (Fig. 1; Table 1).

\section{Diversity and network analysis of microsatellite and pkmsp1 genotyping}

To evaluate the lineage relationships among these $P$. knowlesi infections, microsatellite genotyping and cluster analyses were performed. The overall mean heterozygosity was relatively low $(\mathrm{He}=0.327, \mathrm{SE}=0.043)$, the mean number of alleles was 3.1 , and the multiplicity of infection was 1.032. No significant difference in microsatellite genotypic diversity was found between samples from

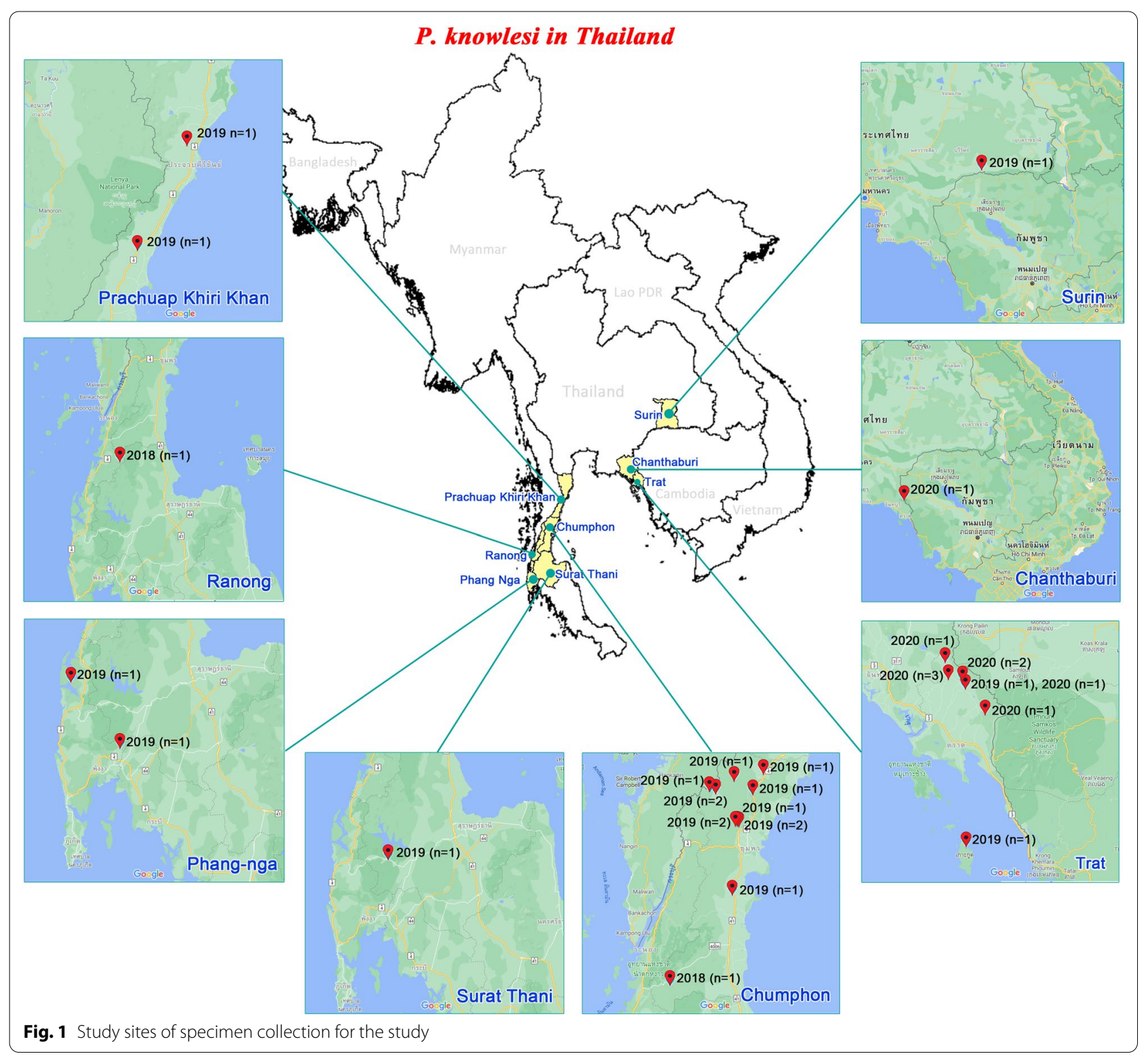


Table 1 Collected samples from iDES for PCR species confirmation

\begin{tabular}{lccccccc}
\hline & PF & PV & PO & PM & PK & Mixed PF+PV & Total \\
\hline 2018 & 29 & 139 & 0 & 0 & 2 & 5 & 175 \\
2019 & 50 & 289 & 0 & 14 & 20 & 2 & 375 \\
2020 & 24 & 369 & 0 & 12 & 9 & 2 & 916 \\
Total & 103 & 797 & 0 & 26 & 31 & 966 \\
\hline
\end{tabular}

eastern and southern Thailand. Haplotype network analysis was performed with the microsatellite marker results (Fig. 2) and showed that P. knowlesi isolated from eastern parts of Thailand, including Surin, Chanthaburi, and Trat, were the same haplotype as $P$. knowlesi parasites isolated from Battambang, Cambodia. Contrastingly, most of the P. knowlesi parasites isolated from southern parts of Thailand, (Prachuap Khiri Khan, Chumphon, Ranong, Surat Thani, and Phang-nga) were in the same lineage as the parasites isolated from Malaysia [24].

Plasmodium knowlesi samples from Thailand were used to create a dendrogram of the merozoite surface protein 1 (pkmsp1), which was compared to previous findings from Thailand [22, 23], and Malaysia [25, 26] was developed (Fig. 3). Plasmodium knowlesi samples collected from southern Thailand, including those connected by nodes, represent descendants from a common ancestor and are more genetically similar to the $P$. knowlesi isolates from Malaysia; while P. knowlesi isolates from eastern Thailand showed high similarity with $P$. knowlesi isolates from Cambodia. Moreover, the malaria isolated from Tak province are closely related to those isolated from Prachuap Khiri Khan.

\section{Pkdhfr gene analysis}

Full-length $p k d h f r$ DNA sequences were amplified successfully from 16 isolates and were aligned with the reference sequence from $P$. knowlesi strain $\mathrm{H}$ (PKNH_0509600) to investigate the variations of the gene. The five mutations in the biding pocket of PkDHFR, equivalent to P. vivax DHFR (I13, F57, S58, S117, I173), were not observed in this study. However, two mutations were found, including Arg34Leu (11/16) and a three-nucleotide deletion at Thr105 (5/16). The PkDHFR

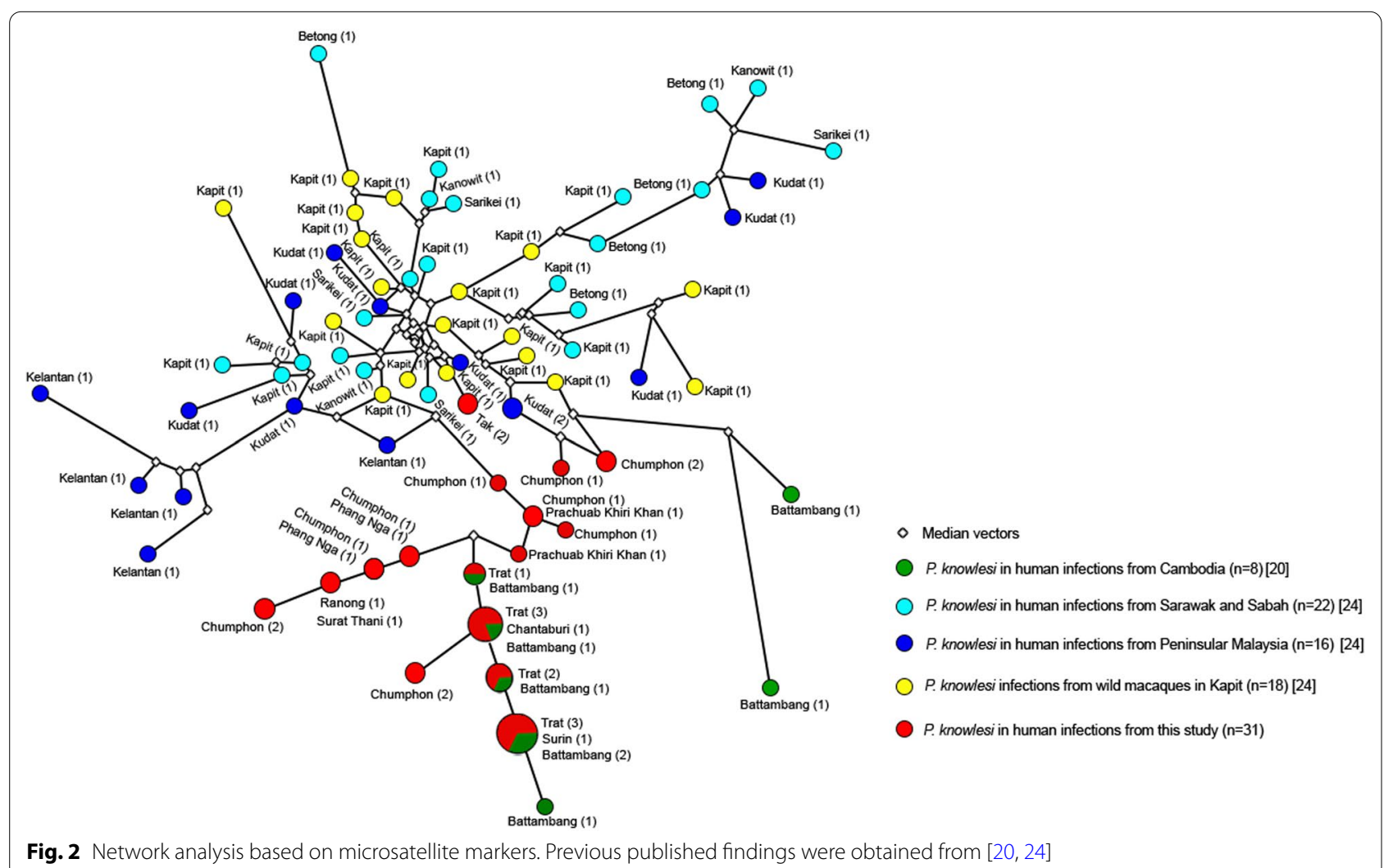




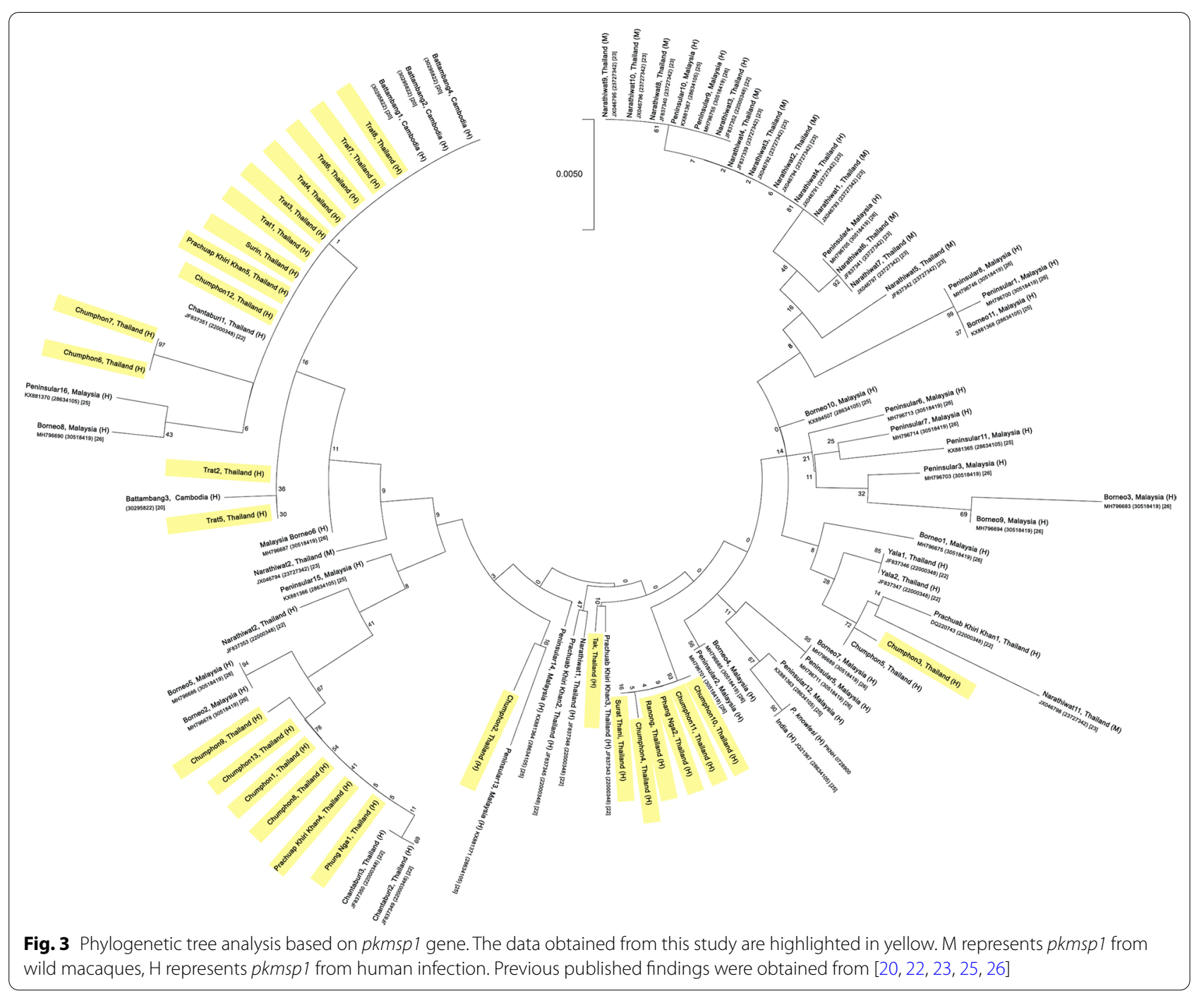

mutation at Arg34Leu is equivalent to that in PvDHFR at Arg34. Although it was an amino acid deletion at Thr105, it did not affect the reading frame and resulted in no premature termination. This position is equivalent to the tandem repeat regions (amino acids 88 and 103 GGDNTS) in PvDHFR, which have been observed previously [30]. The Arg34Leu mutation was found in the isolates from southern Thailand, while the Thr105 deletion was found in isolates from eastern Thailand, which is close to Cambodia. The Thr105 deletion was also found in all $P$. knowlesi isolates $(\mathrm{n}=8)$ from Cambodia.

\section{Homology modelling of PkDHFR mutants}

Three-dimensional structural models of the two mutants (Arg34Leu and Thr105 deletion) in complex with pyrimethamine was constructed and assessed the effect of these mutations on protein-ligand binding. Neither Arg34 nor Thr105 are part of the binding pocket and are located far from the inhibitor-binding site (Fig. 4). As a consequence, neither the mutation at residue 34 nor the deletion of residue 105 disrupted interactions with the pyrimethamine inhibitor, which was confirmed by binding analysis (Fig. 5).

\section{Discussion}

The six GMS countries have endorsed a malaria elimination plan with the goal of eliminating $P$. falciparum malaria by 2024 and all malaria by 2030 [31]. Although the number of $P$. falciparum and $P$. vivax infections has decreased substantially, the incidence of zoonotic malaria from $P$. knowlesi continues to increase in the GMS subregion [32]. The ongoing increase in $P$. knowlesi incidence presents a major challenge to regional malaria control and prevention activities. P. knowlesi infections have been reported in almost all countries in Southeast Asia, and cases have occurred in travelers returning from 

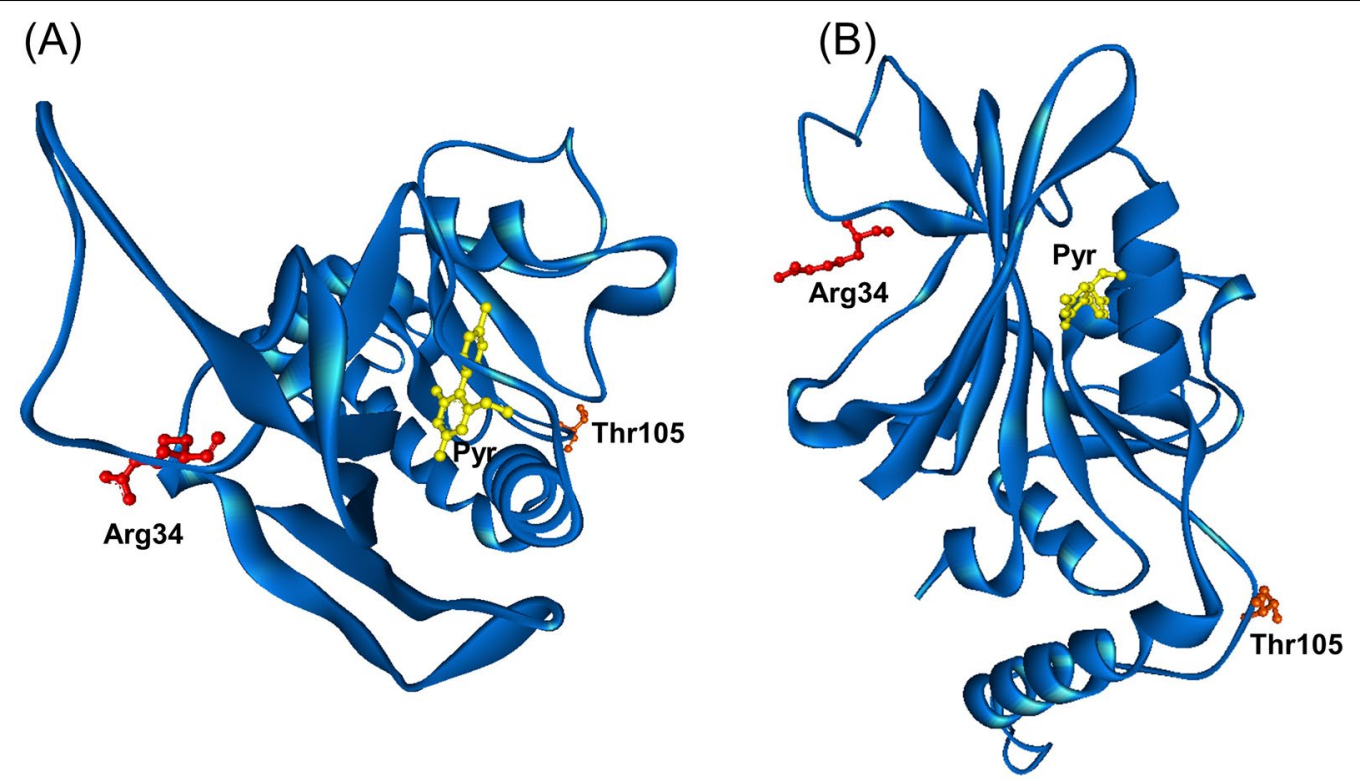

Fig. 4 3D structural models of PkDHFR WT in complex with pyrimethamine. A Top view and B side view. Residues 34 and 105 are depicted in ball and stick colored red and orange, respectively. Pyrimethamine is shown in ball and stick colored yellow

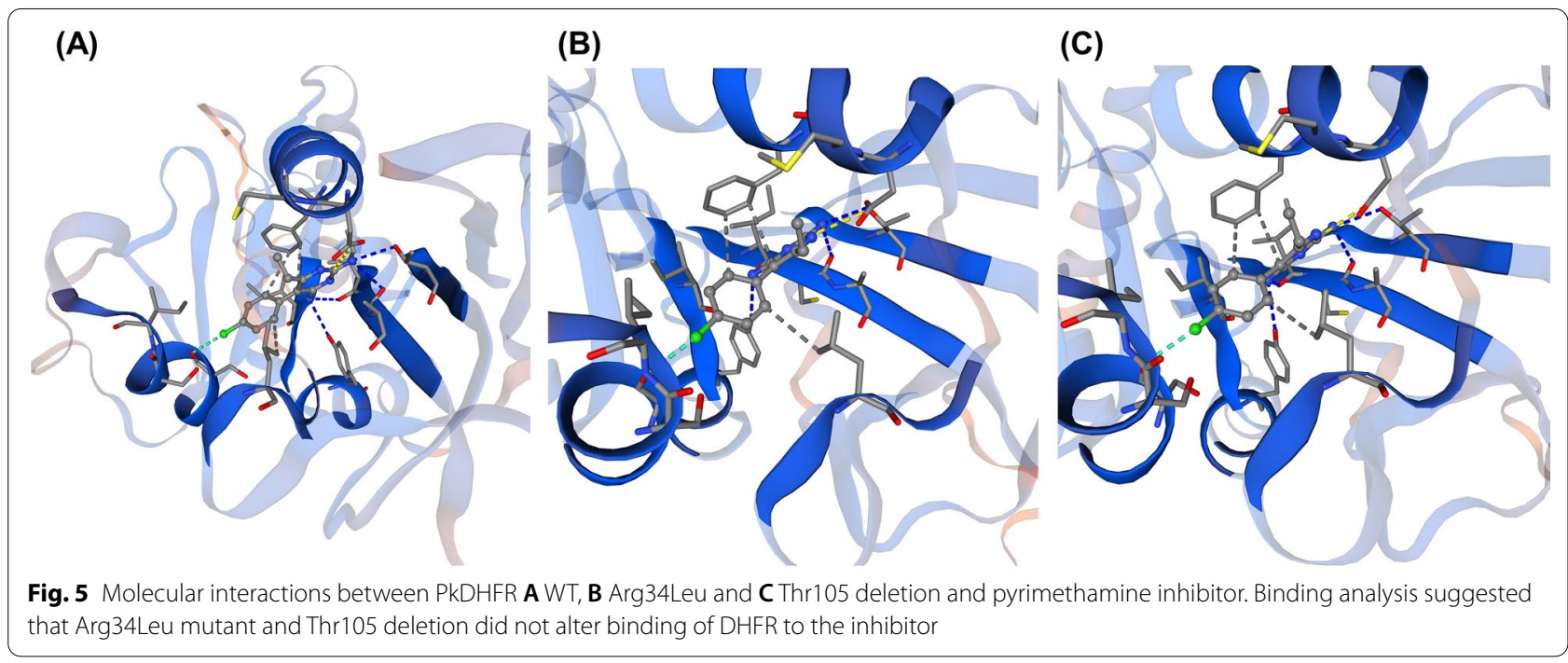

these countries. However, most infections were reported in Malaysian Borneo [32, 33]. The P. knowlesi infections (3.1\%) included in this study were found during the Thailand iDES scheme between 2018 and 2020. Furthermore, asymptomatic $P$. knowlesi infections have previously been found at the Thai-Cambodia border [20]. Plasmodium knowlesi infection can result in high parasitaemia and death, and the diagnosis should be confirmed by PCR [32]. Therefore, highly specific and sensitive molecular tools and identification are required for malaria detection.
To understand the source of $P$. knowlesi infections in Thailand, microsatellite markers and nucleotide sequences of $p k m s p 1$ were analysed for comparison with those of $P$. knowlesi isolated from prior reported findings of Thailand [22, 23], Cambodia [20] and Malaysia [24-26], which share borders with Thailand and may be the sources of the $P$. knowlesi. The microsatellite marker and nucleotide sequencing results of $p k m s p 1$ obtained in this study showed that $P$. knowlesi isolated from southern Thailand were similar to parasites isolated from Malaysia [24-26], suggesting that $P$. knowlesi in southern Thailand 
may be transmitted from Malaysia. Contrastingly, $P$. knowlesi isolated from eastern Thailand were highly similar to those isolated from Cambodia [20], suggesting this country may be the source of the parasites in that area. The clustering of the parasite lineages is likely to be a result of the migration of macaques, as human-to-human transmission has not been identified and the Anopheles vector can only fly a few kilometres. These findings provide information on the source of infection and how $P$. knowlesi malaria may be transmitted.

Molecular clinical and epidemiological studies have clearly shown that specific point mutations in the parasite dihydrofolate reductase gene $(d h f r)$ lead to resistance to pyrimethamine. The mutations cause alterations in crucial residues in the active sites of these enzymes, resulting in reduced drug affinity [34-37]. Plasmodium knowlesi dihydrofolate reductase ( $p k d h f r)$ mutations, found in field isolates from many countries, and ex vivo enzyme activity has been the focus of a number of studies. In this study, Arg34Leu and Thr105 deletions were observed in isolates from Thailand. The three-dimensional structural models of the two mutant proteins in complex with pyrimethamine showed that both Arg34 and Thr105 are not part of the binding pocket and are located far from the inhibitor-binding site, suggesting that the mutation at residue 34 and deletion of residue 105 are not associated with pyrimethamine resistance. Other studies have found a number of $p k d h f r$ mutations, including Arg34Leu from Sabah, Malaysia, with no signs of positive selection [38]. Moreover, ex vivo enzyme activity has also been studied, but there was no association with antifolate resistance [39]. Anti-malarial drug exposure only occurs in human hosts, and if the transmission of $P$. knowlesi remains zoonotic and there is no selection pressure, the malaria would be unlikely to develop anti-malarial resistance. Although there has yet been no anti-malarial resistance reported in $P$. knowlesi, new anti-malarials should be adopted to counteract emerging anti-malarial resistance in the GMS [40]. These new anti-malarials could aid in resolving anti-malarial resistance issues with other Plasmodium species or used in combination to increase anti-malarial efficiency. Furthermore, as monkeys are not treated for malaria, the elimination of P. knowlesi is impossible as long as macaques continue to act as zoonotic hosts. This is particularly evident from the experience in Sarawak in Malaysia, where P. knowlesi is now almost the only remaining malaria infecting humans [41].

\section{Conclusions}

This study on P. knowlesi infections in Thailand demonstrated that the parasites are of the same lineage as P. knowlesi isolated in Cambodia and Malaysia and are still sensitive to pyrimethamine. This is useful information for understanding $P$. knowlesi infections in Thailand and for supporting the continuations of malaria elimination programme.

\section{Abbreviations \\ DNA: Deoxyribonucleic acid; PCR: Polymerase chain reaction; pkmsp 1: P. knowlesi merozoite surfaceprotein 1 gene; pkdhfr: P. knowesi dihydrofolate reductase gene.}

\section{Acknowledgements}

We thank Ms. Jureeporn Duanguppama, Ms. Kanokon Suwannasin, Ms. Wanassanan Madmanee and Ms. Jindarat Kouhathog for their help.

\section{Authors' contributions}

$\mathrm{RS}, \mathrm{AS}, \mathrm{PS}$, and MI contributed to study design. RS, AS, and PS collected samples. RS, PS,CK, and WP undertook laboratory work. CK, SS, UB, and Ml analysed data. RS, SS, AD and MI drafted the manuscript. All authors read and approved the final manuscript.

\section{Funding}

This study was supported by Mahidol university, the Thailand Science Research and Innovation (TSRI), RTA6280006, Thailand. This study was part of the Mahidol-University Oxford Tropical Medicine Research Programme funded by the Wellcome Trust of the United Kingdom. However, this research was funded in whole, or in part, by the Wellcome Trust [220211]. For the purpose of Open Access, the author has applied a CC BY public copyright licence to any Author Accepted Manuscript version arising from this submission.

\section{Availability of data and materials}

All data generated or analysed during this study are included in this published article and its Additional files.

\section{Declarations}

The authors declare that they have no competing interests.

\section{Ethics approval and consent to participate}

Ethical approvals for the study were obtained from the ethical review committees of the Faculty of Tropical Medicine, Mahidol University (MUTM2020082-01). Informed consent was obtained from all participants. Approval for this study was obtained from the Ethics Review Committee for Research in Human Subjects, Faculty of Tropical Medicine, Mahidol University, Thailand (EC approval number: MUTM2020-082-01). Informed consent was obtained from all participants.

\section{Consent for publication}

Not applicable.

\section{Competing interests}

The authors declare that they have no competing interests.

\section{Author details}

${ }^{1}$ Division of Vector Borne Diseases, Department of Disease Control, Ministry of Public Health, Nonthaburi, Thailand. ²Department of Clinical Microscopy, Faculty of Allied Health Sciences, Chulalongkorn University, Bangkok, Thailand. ${ }^{3}$ Mahidol-Oxford Tropical Medicine Research Unit, Faculty of Tropical Medicine, Mahidol University, Bangkok, Thailand. ${ }^{4}$ Department of Molecular Tropical Medicine and Genetics, Faculty of Tropical Medicine, Mahidol University, Bangkok, Thailand. ${ }^{5}$ Centre for Tropical Medicine and Global Health, Nuffield Department of Medicine, University of Oxford, Oxford, UK.

Received: 1 July 2021 Accepted: 18 November 2021

Published online: 03 December 2021 


\section{References}

1. World Health Organization. The "World malaria report 2019" at a glance. Geneva: World Health Organization; 2019.

2. Sudathip P, Saejeng A, Khantikul N, Thongrad T, Kitchakarn S, Sugaram R, et al. Progress and challenges of integrated drug efficacy surveillance for uncomplicated malaria in Thailand. Malar J. 2021;20:261.

3. White NJ. Plasmodium knowlesi: the fifth human malaria parasite. Clin Infect Dis. 2008; 46:172-3.

4. Warren $\mathrm{M}$, Cheong WH, Fredericks HK, Coatney GR. Cycles of jungle malaria in West Malaysia. Am J Trop Med Hyg. 1970;19:383-93.

5. Fong YL, Cadigan FC, Coatney GR. A presumptive case of naturally occurring Plasmodium knowlesi malaria in man in Malaysia. Trans R Soc Trop Med Hyg. 1971;65:839-40.

6. Singh B, Kim Sung L, Matusop A, Radhakrishnan A, Shamsul SS, Cox-Singh J, et al. A large focus of naturally acquired Plasmodium knowlesi infections in human beings. Lancet. 2004;363:1017-24.

7. Singh B, Daneshvar C. Human infections and detection of Plasmodium knowlesi. Clin Microbiol Rev. 2013;26:165-84.

8. Yusof R, Lau YL, Mahmud R, Fong MY, Jelip J, Ngian HU, et al. High proportion of knowlesi malaria in recent malaria cases in Malaysia. Malar J. 2014;13:168.

9. William T, Jelip J, Menon J, Anderios F, Mohammad R, Awang Mohammad TA, et al. Changing epidemiology of malaria in Sabah, Malaysia: increasing incidence of Plasmodium knowlesi. Malar J. 2014;13:390.

10. Sermwittayawong N, Singh B, Nishibuchi M, Sawangjaroen N, Vuddhakul V. Human Plasmodium knowlesi infection in Ranong province, southwestern border of Thailand. Malar J. 2012;11:36

11. Putaporntip C, Hongsrimuang T, Seethamchai S, Kobasa T, Limkittikul $K$, Cui L, et al. Differential prevalence of Plasmodium infections and cryptic Plasmodium knowlesi malaria in humans in Thailand. J Infect Dis. 2009;199:1143-50.

12. Ngernna S, Rachaphaew N, Thammapalo S, Prikchoo P, Kaewnah O, Manopwisedjaroen K, et al. Case report: case series of human Plasmodium knowlesi infection on the Southern Border of Thailand. Am J Trop Med Hyg. 2019;101:1397-401.

13. Jiang N, Chang Q, Sun X, Lu H, Yin J, Zhang Z, et al. Co-infections with Plasmodium knowlesi and other malaria parasites, Myanmar. Emerg Infect Dis. 2010;16:1476-8.

14. Ghinai I, Cook J, Hla TT, Htet HM, Hall T, Lubis IN, et al. Malaria epidemiology in central Myanmar: identification of a multi-species asymptomatic reservoir of infection. Malar J. 2017;16:16.

15. Iwagami M, Nakatsu $M$, Khattignavong P, Soundala P, Lorphachan L, Keomalaphet $S$, et al. First case of human infection with Plasmodium knowlesi in Laos. PLoS Negl Trop Dis. 2018;12:e0006244.

16. Pongvongsa T, Culleton $\mathrm{R}, \mathrm{Ha} \mathrm{H}$, Thanh L, Phongmany P, Marchand RP, et al. Human infection with Plasmodium knowlesi on the Laos-Vietnam border. Trop Med Health. 2018;46:33.

17. Van den Eede P, Van HN, Van Overmeir C, Vythilingam I, Duc TN, le Hung $X$, et al. Human Plasmodium knowlesi infections in young children in central Vietnam. Malar J. 2008;8:249.

18. Marchand RP, Culleton R, Maeno Y, Quang NT, Nakazawa S. Co-infections of Plasmodium knowlesi, P. falciparum, and P. vivax among humans and Anopheles dirus mosquitoes, Southern Vietnam. Emerg Infect Dis. 2011;17:1232-9.

19. Khim N, Siv S, Kim S, Mueller T, Fleischmann E, Singh B, et al. Plasmodium knowlesi infection in humans, Cambodia, 2007-2010. Emerg Infect Dis. 2011;17:1900-2.

20. Imwong M, Madmanee W, Suwannasin K, Kunasol C, Peto TJ, Tripura R, et al. Asymptomatic natural human infections with the simian malaria parasites Plasmodium cynomolgi and Plasmodium knowlesi. J Infect Dis. 2019, 219:695-702.

21. WHO. Malaria rapid diagnostic test performance. Results of WHO product testing of malaria RDTs: round 8 (2016-2018). Geneva: World Health Organization, 2018.

22. Jongwutiwes S, Buppan P, Kosuvin R, Seethamchai S, Pattanawong U, Sirichaisinthop J, et al. Plasmodium knowlesi Malaria in humans and macaques, Thailand. Emerg Infect Dis. 2011;17:1799-806.
23. Putaporntip C, Thongaree S, Jongwutiwes S. Differential sequence diversity at merozoite surface protein-1 locus of Plasmodium knowlesi from humans and macaques in Thailand. Infect Genet Evol. 2013;18:213-9.

24. Divis PC, Singh B, Anderios F, Hisam S, Matusop A, Kocken CH, et al. Admixture in humans of two divergent Plasmodium knowlesi populations associated with different macaque host species. PLoS Pathog. 2015, 11:e1004888.

25. Yap NJ, Goh XT, Koehler AV, William T, Yeo TW, Vythilingam I, et al. Genetic diversity in the C-terminus of merozoite surface protein 1 among Plasmodium knowlesi isolates from Selangor and Sabah Borneo, Malaysia. Infect Genet Evol. 2017;54:39-46.

26. Yap NJ, Vythilingam I, Hoh BP, Goh XT, Muslim A, Ngui R, et al. Genetic polymorphism and natural selection in the C-terminal $42 \mathrm{kDa}$ region of merozoite surface protein-1 (MSP-1) among Plasmodium knowlesi samples from Malaysia. Parasit Vectors. 2018;11:626.

27. Snounou G, Viriyakosol S, Zhu XP, Jarra W, Pinheiro L, do Rosario VE, et al. High sensitivity of detection of human malaria parasites by the use of nested polymerase chain reaction. Mol Biochem Parasitol. 1993;61:315-20.

28. Waterhouse A, Bertoni M, Bienert S, Studer G, Tauriello G, Gumienny $\mathrm{R}$, et al. SWISS-MODEL: homology modelling of protein structures and complexes. Nucleic Acids Res. 2018;46:W296-303.

29. Morris AL, MacArthur MW, Hutchinson EG, Thornton JM. Stereochemical quality of protein structure coordinates. Proteins. 1992;12:345-64.

30. Imwong M, Pukrittakayamee S, Looareesuwan S, Pasvol G, Poirreiz J, White NJ, et al. Association of genetic mutations in Plasmodium vivax dhfr with resistance to sulfadoxine-pyrimethamine: geographical and clinical correlates. Antimicrob Agents Chemother. 2001;45:3122-7.

31. WHO. Strategy for malaria elimination in the Greater Mekong Subregion: 2015-2030. Geneva: World Health Organization, 2015.

32. WHO. Expert consultation on Plasmodium knowlesi malaria to guide malaria elimination strategies. Geneva: World Health Organization, 2017.

33. Anstey NM, Grigg MJ. Zoonotic malaria: the better you look, the more you find. J Infect Dis. 2019;219:679681.

34. Foote SJ, Cowman AF. The mode of action and the mechanism of resistance to antimalarial drugs. Acta Trop. 1994;56:157-71.

35. Matthews DA, Alden RA, Bolin JT, Freer ST, Hamlin R, Xuong N, et al. Dihydrofolate reductase: $\mathrm{x}$-ray structure of the binary complex with methotrexate. Science. 1977;197:452-5.

36. Peterson DS, Walliker D, Wellems TE. Evidence that a point mutation in dihydrofolate reductase-thymidylate synthase confers resistance to pyrimethamine in falciparum malaria. Proc Natl Acad Sci USA. 1988;85:9114-8.

37. Volz KW, Matthews DA, Alden RA, Freer ST, Hansch C, Kaufman BT, et al. Crystal structure of avian dihydrofolate reductase containing phenyltriazine and NADPH. J Biol Chem. 1982;257:2528-36.

38. Grigg MJ, Barber BE, Marfurt J, Imwong M, William T, Bird E, et al. Dihydrofolate-reductase mutations in Plasmodium knowlesi appear unrelated to selective drug pressure from putative human-to-human transmission in Sabah, Malaysia. PLoS ONE. 2016;11:e0149519.

39. Ittarat W, Pornthanakasem W, Mungthin M, Suwandittakul N, Leelayoova $\mathrm{S}$, Tarnchompoo B, et al. Characterization of Plasmodium knowlesi dihydrofolate reductase-thymidylate synthase and sensitivity to antifolates. Parasitol Int. 2018;67:787-92.

40. WHO. Status report on artemisinin and ACT resistance. Geneva: World Health Organization. 2017.

41. Feachem RGA, Chen I, Akbari O, Bertozzi-Villa A, Bhatt S, Binka F, et al. Malaria eradication within a generation: ambitious, achievable, and necessary. Lancet. 2019;394:1056-112.

\section{Publisher's Note}

Springer Nature remains neutral with regard to jurisdictional claims in published maps and institutional affiliations. 